\title{
In Vivo Dynamics of Axon Pathfinding in the Drosophila CNS: A Time-Lapse Study of an Identified Motorneuron
}

\author{
Michael J. Murray, ${ }^{1}$ David J. Merritt, ${ }^{2}$ Andrea H. Brand, ${ }^{3}$ Paul M. Whitington ${ }^{1}$ \\ ${ }^{1}$ Division of Molecular and Cellular Biology, School of Biological Sciences, University of New \\ England, Armidale, NSW 2351, Australia \\ ${ }^{2}$ Department of Entomology, University of Queensland, St Lucia, Qld 4072, Australia \\ ${ }^{3}$ The Wellcome/CRC Institute, University of Cambridge, Tennis Court Road, Cambridge \\ CB2 1QR UK
}

Received 17 April 1998; accepted 25 June 1998

\begin{abstract}
We developed a system for timelapse observation of identified neurons in the central nervous system (CNS) of the Drosophila embryo. Using this system, we characterize the dynamics of filopodia and axon growth of the motorneuron RP2 as it navigates anteriorly through the CNS and then laterally along the intersegmental nerve (ISN) into the periphery. We find that both axonal extension and turning occur primarily through the process of filopodial dilation. In addition, we
\end{abstract}

used the GAL4-UAS system to express the fusion protein Tau-GFP in a subset of neurons, allowing us to correlate RP2's patterns of growth with a subset of axons in its environment. In particular, we show that RP2's sharp lateral turn is coincident with the nascent ISN. (c) 1998 John Wiley \& Sons, Inc. J Neurobiol 37: 607-621, 1998

Keywords: Drosophila; growth cone; time lapse; motorneuron; axon pathfinding
An understanding of axon pathfinding involves a description of the changing morphology of growing axons together with knowledge of the molecular mechanisms underlying those changes. While patterns of growth for identified neurons can be reconstructed from axonal morphologies in fixed embryos, a description of the dynamics of axon growth requires time-lapse observation. In recent years, the combination of nontoxic fluorescent dyes and low-light-level imaging has permitted neurons to be observed navigating in vivo for extended periods without affecting normal pathfinding. Such studies have been carried out in both vertebrates (Eisen et al., 1986; Harris et al., 1987; Kaethner and Stuermer, 1992; Sretavan and

Correspondence to: M. J. Murray

(C) 1998 John Wiley \& Sons, Inc. CCC 0022-3034/98/040607-15
Reichardt, 1993; Godement et al., 1994; Halloran and Kalil, 1994) and invertebrates (O'Connor et al., 1990; Myers and Bastiani, 1993). An important advantage of invertebrates and simple vertebrates such as the zebrafish (Kaethner and Stuermer, 1992) is that individual neurons can be identified and observed growing along stereotypic pathways. This allows growth cone behavior and cytoskeletal rearrangements to be correlated with identifiable extracellular guidance cues. For example, in the grasshopper limb bud, Bentley and colleagues were able to correlate patterns of growth cone behavior with changing extracellular substrates (O'Connor et al., 1990), and documented the changing arrangements of both microtubules (Sabry et al., 1991) and microfilaments (O'Connor and Bentley, 1993) during known steering events. However, one limitation with the grasshopper as a model 


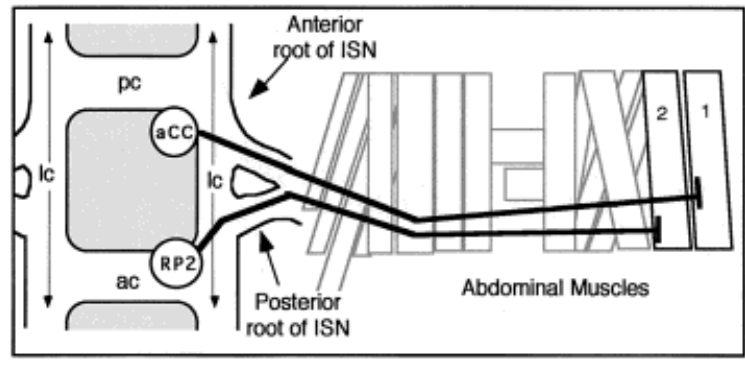

Figure 1 Schematic of one segment of the CNS and body wall of the Drosophila embryo, showing the mature projections of motorneurons RP2 and aCC. aCC pioneers the anterior root of the intersegmental nerve, arborising on muscle 1. RP2's axon exits the CNS via the posterior root of the ISN and arborises on muscle 2. Anterior is up. 1c $=$ longitudinal connective; $\mathrm{ac}=$ anterior commissure; $\mathrm{pc}$ $=$ posterior commissure.

system is that hypotheses about the role played by specific genes cannot be readily tested by mutant analysis.

In this article, we describe the development of a system for time-lapse observation of living neurons navigating in the embryo of Drosophila melanogaster, an invertebrate suited to genetic and molecular manipulations. In Drosophila, mutations in a number of identified genes result in axon pathfinding errors and abnormal development of axon pathways (e.g., Goodman, 1996; Desai et al., 1997). Time-lapse observations in these mutants will shed light on the role played by specific gene products in general growth cone dynamics and specific steering events, and in doing so lead to a better understanding of the cellular events underlying the development of gross defects in the nervous system. Time-lapse observations have previously been used in Drosophila to document the dynamic behavior of filopodial exploration in the embryonic body wall (Keshishian et al., 1993). In this article, we describe the dynamics of filopodia and axon growth of the motorneuron RP2 in wild-type embryos, as it navigates anteriorly through the central nervous system (CNS) and then makes a distinct lateral turn along the intersegmental nerve (ISN) out to its target, muscle 2 (Sink and Whitington, 1991a) (Fig. 1).

We have found the process of filopodial dilation, in which a filopodium persists and thickens to become the newly formed neurite, to be an important mechanism for both axonal elongation and turning. Filopodial dilation, first seen in vitro (Letourneau, 1975; Hammarback and Letourneau, 1986), was described in detail by O'Connor et al. (1990) and has subsequently been observed in other in vivo systems (Mason and Godement, 1992; Myers and Bastiani, 1993).
In this article, we show that filopodial dilation also occurs in Drosophila, during both RP2's anterior progression and its lateral turn into the ISN.

In addition to the wild-type characterization, we have used the GAL4/UAS transcriptional activation system (Fischer et al., 1988; Brand and Perrimon, 1993) to observe RP2 navigating in an embryo in which a subset of cells, including the motorneuron $\mathrm{aCC}$, express green fluorescent protein fused to the microtubule binding protein, Tau (Prasher et al., 1992; Chalfie et al., 1994; Brand, 1995). This has allowed us to correlate specific morphological features of RP2's growth cone with the surrounding axonal environment. In particular, we find that RP2's lateral turn, often mediated by the dilation of a single filopodium, is coincident with the nascent ISN.

\section{MATERIALS AND METHODS}

\section{Preparation, Staging, Dissection, and Culturing of Embryos}

Oregon-R wild-type embryos of D. melanogaster were collected from yeast-pasted agar plates, chemically dechorionated by $5 \mathrm{~min}$ agitation in $50 \%$ commercial bleach, and washed in Drosophila saline $(6.50 \mathrm{~g} \mathrm{NaCl}, 0.14 \mathrm{~g} \mathrm{KCl}$, $0.20 \mathrm{~g} \mathrm{NaHCO}_{3}, 0.12 \mathrm{~g} \mathrm{CaCl}_{2}, 0.01 \mathrm{~g} \mathrm{NaH}_{2} \mathrm{PO}_{4} \cdot 2 \mathrm{H}_{2} \mathrm{O}$ in $889 \mathrm{~mL} \mathrm{dH_{2 }} \mathrm{O}$ ). Accurate staging was achieved by choosing embryos at the midpoint of germ-band retraction-a time when the germ band is moving rapidly - and then incubating them whole (i.e., undissected) at $25^{\circ} \mathrm{C}$ in saline for a given period of time. Stages given in this report are specified as the number of minutes after this morphological stage, which corresponds to midstage 12 in Campos-Ortega and Hartenstein's staging scheme (1985).

For time-lapse observations, embryos were dissected at the desired stage (usually $t=45-50 \mathrm{~min}$ ) as previously described (Sink and Whitington, 1991b) and cultured in a humidified chamber formed between the slide and the objective using a perspex ring sealed with white petroleum jelly. Embryos were cultured in either saline $(n=18)$ or M3 (with L-alanine replacing $\beta$-alanine, $888 \mathrm{mg}$ of K.glutamate and $\mathrm{KHCO}_{3}$ omitted) (Shields and Sang, 1977) supplemented with $10 \%$ fetal calf serum (FCS) $(n=4)$. The culture medium was maintained at approximately $25^{\circ} \mathrm{C}$ during time-lapse observations.

\section{Dil Injections}

For time-lapse observations, the soma of RP2 was identified under Nomarski optics using a Leitz $\times 100$ water-immersion objective. A 30-60 M $\Omega$ microelectrode pulled on a BrownFlaming horizontal puller (Sutter Instrument Co.) was placed against the cell membrane, with care being taken to avoid puncturing the cell. Under fluorescent illumination, 


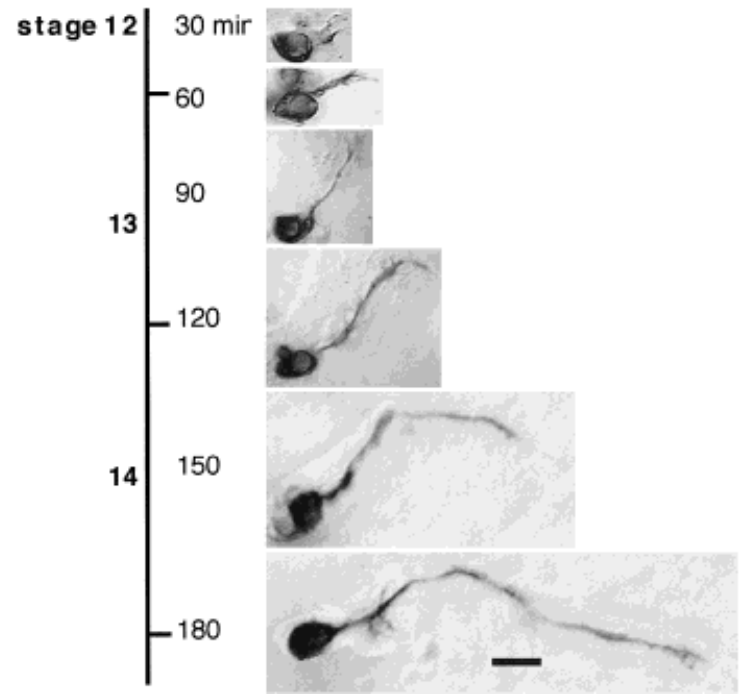

Figure 2 Time course of development of RP2 in whole embryos. Embryos were chosen at midstage 12, incubated for periods separated by 30-min intervals, and fixed, and RP2 was injected with DiI and photoconverted (see Materials and Methods for details). At $30 \mathrm{~min}$, RP2 has just begun axonogenesis with the extension of a broad process in the anterolateral direction. At $60 \mathrm{~min}$, this process has extended further and is narrower. At $90 \mathrm{~min}$, the axon has extended anteriorly into the vicinity of the ISN. At $120 \mathrm{~min}$, the axon has begun to turn laterally, and by $180 \mathrm{~min}$, the lateral branch has extended into the periphery. Bar $=10$ $\mu \mathrm{m}$.

attenuated with a $10 \%$ neutral density filter and using a TRITC filter set (Chroma Technology), a $0.01 \%$ DiI solution in 1:9 dimethyl sulfoxide (DMSO):ethanol was iontophoretically injected by applying a $0.5-$ to $1.0-\mathrm{nA}$ DC depolarizing current until dye was seen to begin diffusing across the cell body (typically 1-2 s). At this time, the fluorescent illumination and current were immediately turned off. For measurements of axon growth in whole embryos, cells were injected and photoconverted as previously described (Merritt and Whitington, 1995).

\section{Time-Lapse Observations}

Time-lapse observations were carried out on a Zeiss Axioskop equipped with a UniBlitz shutter, an ASI focus controller, and a COHU 4913 integrating camera connected to a Scion LG-3 frame grabber. This hardware was controlled with a modified version of the NIH Image software (available by anonymous ftp at zippy.nimh.nih.gov) running on a Macintosh Quadra 800 computer.

At 1-min intervals, the shutter was opened for 0.5-2 s, the excitation light passed through a $1 \%$ neutral density filter, and the emitted signal was integrated on the COHU on-chip integrating CCD at 24 frames/s. An ASI focus controller was used to monitor and change the $z$ position to keep the region surrounding RP2's lateral turn in focus. This meant that at later stages, RP2's soma and its axon, which extended ventro-laterally out of the CNS, were out of focus.

Only time-lapse sequences in which RP2 followed a normal trajectory-turning laterally and extending out of the CNS into the periphery-have been used for the characterizations and statistics reported here. These 22 sequences were collected using either M3 medium $(n=4)$ or saline $(n=18)$. Injected cells showed a range of behaviors. Of the 41 attempted time-lapse sequences using saline, there were 18 in which RP2 showed vigorous growth and projected normally, seven in which RP2 extended as far as the ISN but either did not form a lateral branch or formed a branch but subsequently retracted it, six in which RP2 continued to extend filopodia but made no forward progress, nine in which RP2 showed rapid retraction/fragmentation, and one in which RP2 showed vigorous growth but, in addition to extending the usual lateral branch, also formed a lateral branch in the next anterior segment [see Fig. 6(D)].

Lengths of filopodia and axons were measured by importing image sequences into Director 4.0 (MacroMedia) and positioning markers along the lengths of processes. Measurements were restricted to those frames in which the extent of the filopodium/axon was clear. When measuring the time taken for filopodia to reach their maximum length (Fig. 8), only those filopodia whose initial outgrowth was in focus (13 out of 31) were included. Following dilation

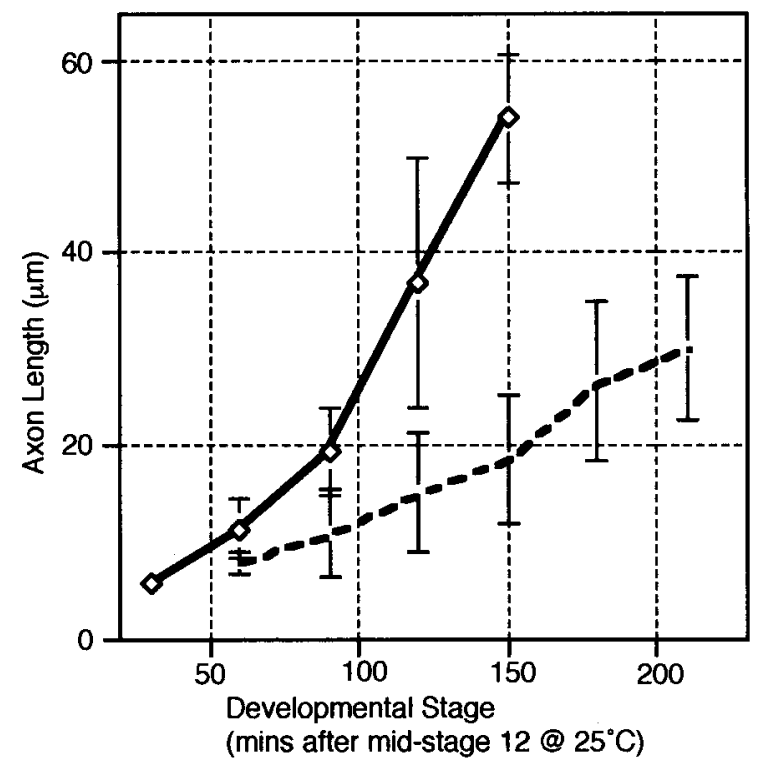

Figure 3 Rates of axonal extension in whole embryos and in vivo. Solid line shows mean lengths of RP2's axon in whole embryos fixed at successive developmental stages (error bars give standard deviations). Dotted line shows mean length of axons in time-lapse sequences, calculated at 30-min intervals. Sample sizes for whole embryos were: 30 $\min , n=7 ; 60 \min , n=29 ; 90 \min , n=15 ; 120 \min$, $n=11 ; 150 \mathrm{~min}, n=6$, and for time-lapse sequences, 60 $\min , n=4 ; 90 \min , n=12 ; 120 \min , n=13 ; 150 \mathrm{~min}$, $n=12 ; 180 \min , n=7 ; 210 \min , n=2$. 

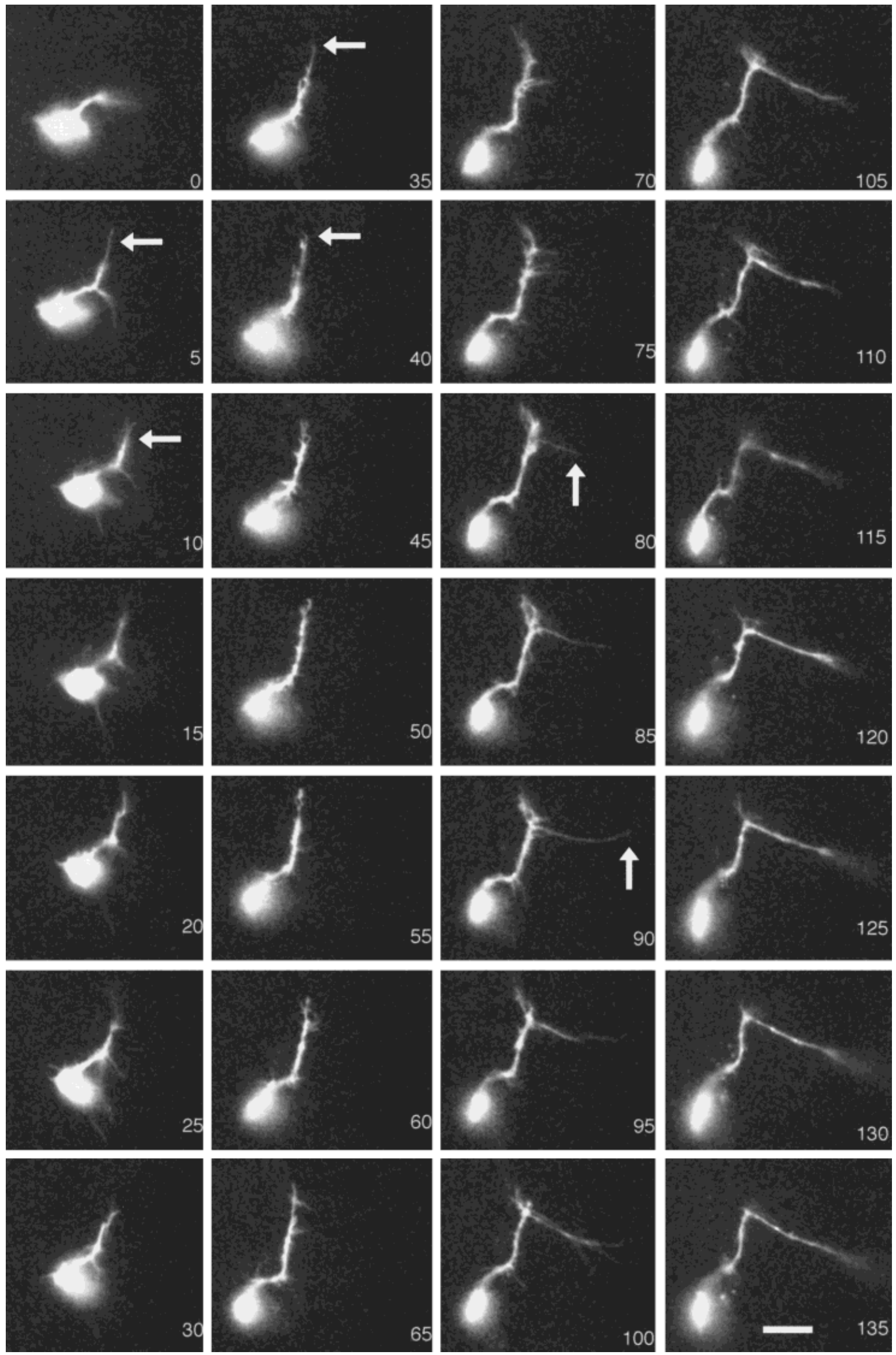

Figure 4 
events, markers indicating the tip of the axon were advanced as soon as the process was clearly thickened and stable.

\section{Construction of UAS-Tau-GFP Flies}

Green fluorescent protein with mutations S65T and I167T was amplified by PCR from plasmid pS65T,I167T (a kind gift from J. Pines) and ligated to the first 382 amino acids of bovine Tau (as reconstructed in pBT43-12 by Butner and Kirschner (1991) and Callahan and Thomas, 1994). The Tau-GFP fusion was then subcloned into pUAST (Brand and Perrimon, 1993) and transgenic lines generated by injection of DNA, prepared using the Qiagen midiprep protocol, as previously described (Brand and Perrimon, 1993). Several independent transformants were obtained.

The excitation spectrum of wild-type GFP has two peaks: one at $395 \mathrm{~nm}$ and a second, lower peak at $475 \mathrm{~nm}$. The two point mutations in the GFP coding sequence, S65T (Heim et al., 1995) and I167T (Heim et al., 1994), shift the excitation spectrum of GFP toward a single excitation peak near $475 \mathrm{~nm}$ with a peak of emission near $508 \mathrm{~nm}$. Tau$\mathrm{GFP}^{65 / 167}$ is visible by epifluorescence using most conventional fluorescein isothiocyanate (FITC) filter sets, and is ideal for imaging by confocal microscopy, using the 488-nm line produced by either an argon ion or krypton/argon mixed-gas laser. The Tau-GFP ${ }^{65 / 167}$ fusion protein fluoresces more brightly than Tau-GFP ${ }^{\text {wild type }}$ or Tau-GFP carrying either the S65T or I167T mutation alone (Brand, 1995; A. Brand, unpublished data).

\section{Time-Lapse Observations of Dil-Labeled RP2 in $\mathrm{ftz}_{\mathrm{ng}}$-GAL4, UAS-Tau-GFP Embryos}

$\mathrm{ftz}_{\text {ng }}$-GAL4/TM3 flies were crossed with flies carrying a single UAS-Tau-GFP insert, homozygous on the second chromosome. Embryos were collected, dechorionated, and dissected as previously described. Embryos expressing TauGFP were examined for hemisegments in which the ISN was clearly visible. RP2 was then injected with a $0.001 \%$ DiI solution in $100 \%$ ethanol. At 2-min intervals, an image of RP2 was captured with a TRITC filter set (Chroma Tech.) and 1-2 s integration with a $10 \% \mathrm{ND}$ filter, followed $30 \mathrm{~s}$ later by an image of the Tau-GFP-positive cells using an FITC filter set (XF100; Omega Optical) with 4-10 s of integration and no ND filter. FITC and TRITC images were then contrast-enhanced and overlayed in either Photoshop 4.0 (Adobe) or NIH Image.

Tau-fusion proteins can interfere with mitosis in rapidly dividing tissues, such as the imaginal discs. For example, the pupal thorax is eliminated in flies expressing tau- $\beta$ galactosidase driven by engrailed-GAL4, leading to $100 \%$ lethality. Tau-GFP causes milder phenotypes: Flies expressing tau-GFP are viable, but exhibit a posterior wing defect (A. Brand, unpublished data). However, we have seen no obvious defects in the embryonic CNS when expressing tau-GFP, and in the example presented in this article, we believe that the Tau-GFP/DiI time-lapse sequences are effectively wild type. Both the positioning of Tau-GFP labelled pathways and RP2's dynamic behavior appeared normal. In addition, the levels of fluorescent excitation of the Tau-GFP fluorochrome did not appear to hinder the development of the Tau-GFP-positive pathways such as the MP1/dMP2 pathway, or the normal lateral contraction of the CNS. Furthermore, flies expressing Tau-GFP were viable and fertile.

\section{RESULTS}

\section{Dynamics of Motorneuron RP2's Axonal Outgrowth}

Prior to the collection of time-lapse data, the timecourse of outgrowth of RP2 was reconstructed from axonal morphologies in whole embryos fixed at stages separated by intervals of 30 min (Fig. 2). RP2's early development within the CNS can be divided into three periods:

1. axonogenesis and the formation of a short anterolateral process (30-60 min) (Fig. 2)

2. anterior growth up to the ISN (60-90 min) (Fig. 2)

3. lateral extension down the ISN and out of the CNS (120-180 min) (Fig. 2)

Figure 4 Time-lapse sequence of RP2's axon navigating out of the CNS. RP2 was injected with DiI, and images were captured at 1-min intervals for a period of $135 \mathrm{~min}$. RP2's axon begins as a short anterolateral process extending out from the soma. A filopodium extends anteriorly ( $0-5 \mathrm{~min})$ and dilates (arrows, 5-10 min), reorienting the growth cone in an anterior direction. Further filopodial extensions (arrow, $35 \mathrm{~min}$ ) and dilation (35-40 min) result in continued axonal advance in an anterior direction. At $80 \mathrm{~min}$, a filopodium emerges from behind the leading edge of the axon (arrow) and extends laterally for $\sim 20 \mu \mathrm{m}$ (arrow, $90 \mathrm{~min}$ ). This filopodium dilates and the anterior branch is gradually resorbed back into the axon as the lateral branch is elaborated. By 135 min, the growth cone has extended well into the periphery (and ventrally out of focus) and the axon has attained a mature morphology, i.e., more even width, smoother bends and reduced filopodial activity. Bar $=10 \mu \mathrm{m}$. 

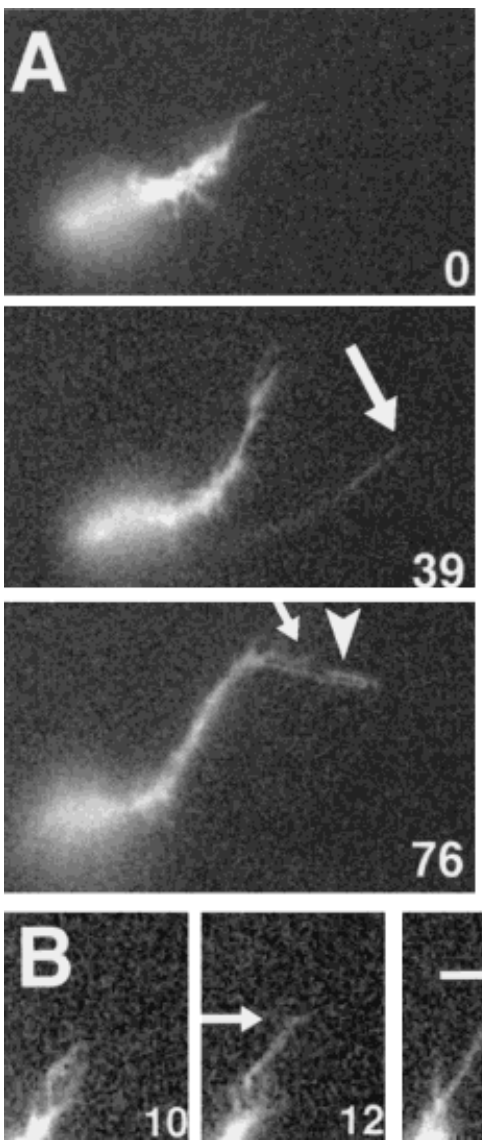
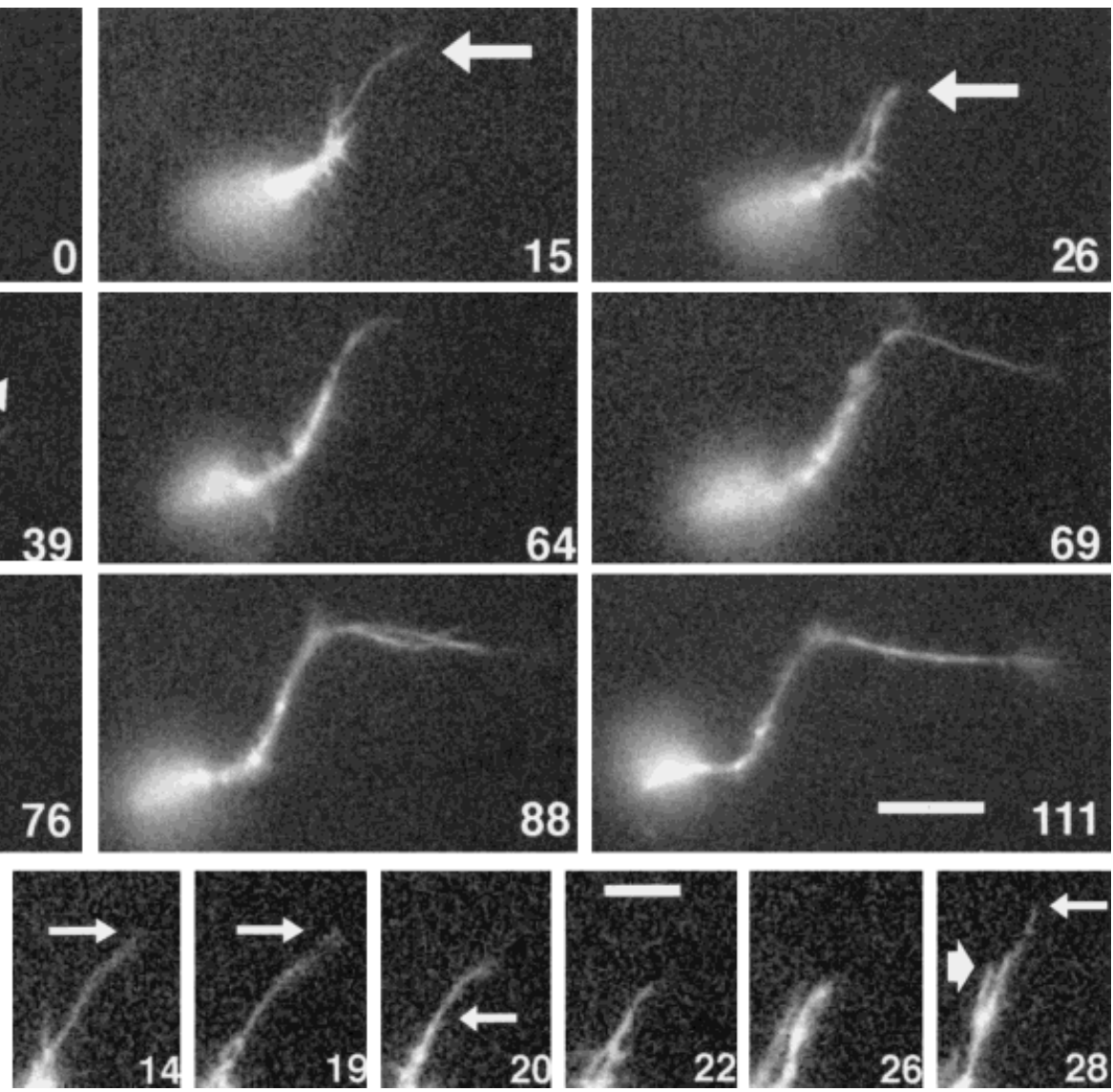

Figure 5 (A) Time-lapse sequence of RP2, in which the lateral branch forms from the tip of the growing axon (69 $\mathrm{min}$ ). Note the dilation of an anterior filopodium (arrows, 15-26 min) and a long filopodium at $39 \mathrm{~min}$, which rapidly reached $\sim 20 \mu \mathrm{m}$ but did not dilate. The filopodium at $69 \mathrm{~min}$ retracts and reextends at $180^{\circ}$ to original direction (arrowhead, $76 \mathrm{~min}$ ). A second lateral filopodium forms (arrow, $76 \mathrm{~min}$ ), and dilates as the original filopodium is resorbed (88-111 min). (B) Detail of an anterior filopodial dilation sequence. A filopodium extends (10-14 min), pauses (14-19 min), and is then partially retracted (19-22 min) as the shaft thickens first at the base (arrow, $20 \mathrm{~min}$ ) and subsequently to a distance approximately half the length of the original filopodium (26 min). At time $28 \mathrm{~min}$, a secondary process (apparently thicker than a filopodium) extends from the side of the thickened shaft (wide arrow), and a new filopodium extends from the tip (arrow). Bars: (A) $10 \mu \mathrm{m}$, (B) $5 \mu \mathrm{m}$.

At any given stage, there is considerable variation in axon length, particularly during the period in which RP2's axon turns laterally (120 min) (Fig. 3). Average rates of axon growth increase once RP2 is extending along the ISN (Figs. 2 and 3).

Time-lapse images were collected at 1-min intervals in a dissected fillet preparation, in which the body wall is flattened onto the slide and the dorsal surface of the CNS is revealed. Time-lapse observations were consistent with observations from whole embryos, both in terms of the morphologies and patterns of growth, and the relative rates of growth before and after joining the ISN, although the rates of axonal elongation were slower (see below). The time-lapse observations presented here are based on 22 sequences (see Materials and Methods) beginning at stages 60-90 $\min (n=20)$ and $100-120 \min (n$ $=2)$. In most cases $(n=12)$, RP2's anterolateral process had already formed but the axon had not yet migrated anteriorly [Fig. 4: 0 min; Fig. 5(A): 0 min]. In the other cases $(n=10), \mathrm{RP} 2$ 's axon had already extended anteriorly to the vicinity of the ISN. RP2's anterolateral process is typically very motile and is the center of much filopodial activity. Filopodia show no obvious biases in distribution around the cell and can apparently arise from all parts of the soma and axon [e.g. Fig. 6(B)].

RP2's axon then migrates anteriorly to the ISN. In 

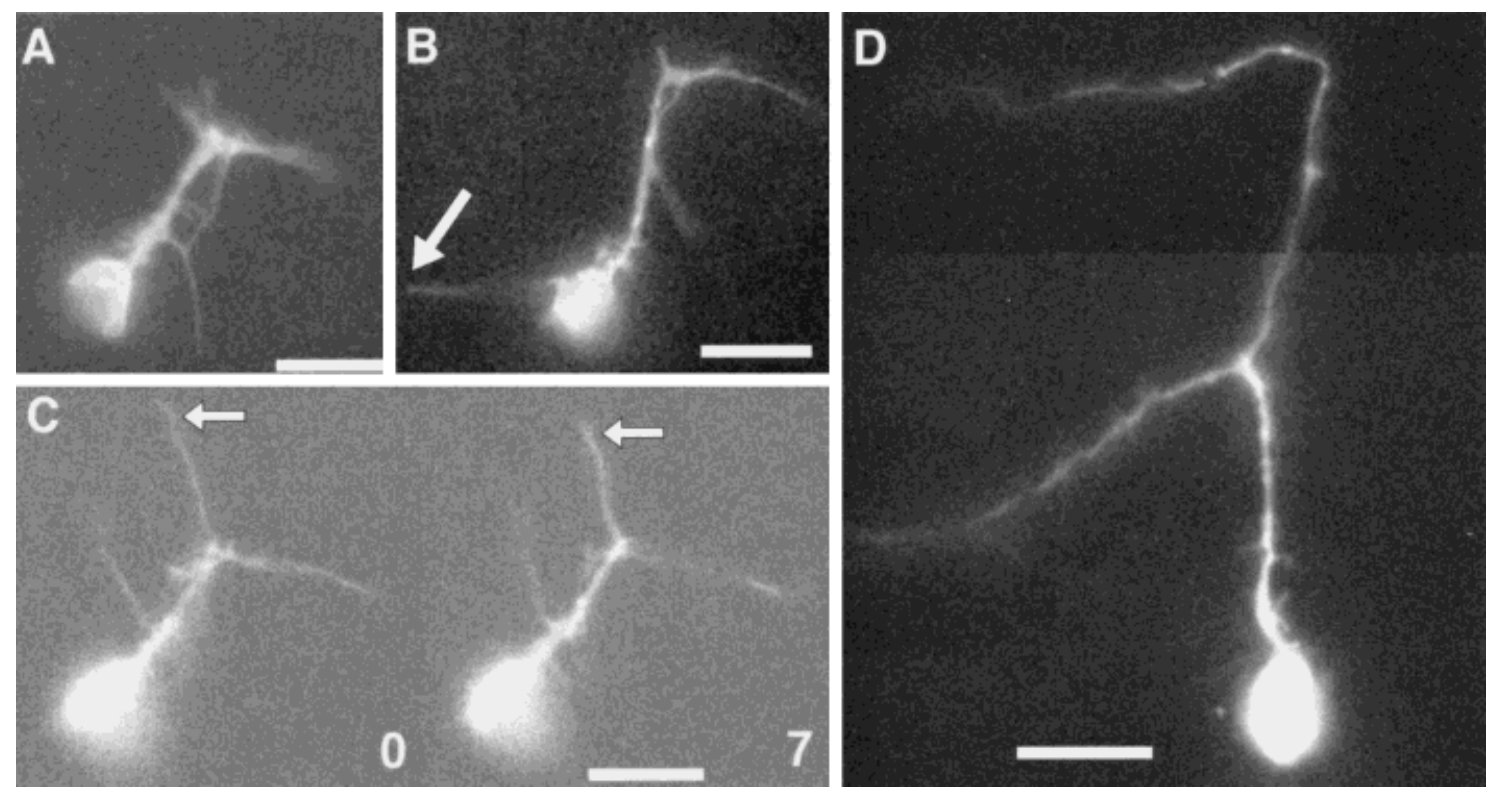

Figure 6 Selection of axon morphologies from four different time-lapse sequences. (A) RP2's axon forms a typical fan shape at the ISN. (B) Filopodia can continue to extend from the mature axon, one of which extends across the commissure (arrow). (C) Antero-medial branch forms by the thickening of a filopodium (arrows, 0-7 min). (D) Aberrant ectopic branch forms in next anterior segment. Bars $=10 \mu \mathrm{m}$.

8 of 12 cases, this anterior progression was observed to occur by a process of filopodial dilation-a filopodium extends some distance anteriorly [Fig. 4: 5 min; Fig. 5(A): $15 \mathrm{~min}$ ], persists, and thickens to become the newly formed neurite. New filopodia could then extend anteriorly from this more advanced position [Fig. 4: $35 \mathrm{~min}$; Fig. 5(B): $28 \mathrm{~min}$ ] and again dilate. In some cases, the extension and dilation of a single filopodium was sufficient to bring the neurite into the vicinity of the ISN. The average maximum length of filopodia that dilated (and whose extent was clear) was $5.3 \pm 2.6 \mu \mathrm{m}(n=11)$. In the other four sequences, a dilation was not recorded owing to a lack of image quality $(n=3)$ or inadequate temporal resolution $(n=1)$.

A typical dilation sequence is shown in Figure 5(B). A filopodium extends anteriorly (10-14 min) and pauses (14-19 min). The filopodium then begins to thicken at the base $(20 \mathrm{~min})$. As the shaft continues to thicken, the tip of the original filopodium is partially retracted so that at $26 \mathrm{~min}$ the neurite has advanced to approximately half the length of the original filopodium. At 28 min, a filopodium emerges from this more advanced position.

Filopodial dilation was also the method by which RP2's axon turned laterally. Of the 20 sequences in which we were able to observe RP2 turning (two had already turned), only 10 were in clear focus, and in each of these cases filopodial dilation was observed. Lateral dilations followed similar patterns to dilations during the anterior progression but typically involved longer filopodia, and therefore provided a clearer view of this process. Lateral filopodia that dilated (and whose extent was clear) averaged a maximum length of $12.4 \pm 3.6 \mu \mathrm{m}(n=7)$.

Figure 7 shows three sequences demonstrating a range of behaviors seen during dilation. In Figure 7(D), a filopodium is seen extending laterally and ventrally, out of focus, as dilation proceeds. The thickening of the shaft begins at the base $(5 \mathrm{~min})$ and is then seen at discontinuous locations along the shaft (e.g., 11 and $18 \mathrm{~min}$ ). Figure 7(E) shows another sequence in which thickening begins at the proximal end of the filopodium (4 min).

Another common feature of dilation sequences is the emergence of secondary filopodia and/or thicker processes from the side of the thickening shaft: These are oriented in the same general direction as the original filopodium [Fig. 5(B): $28 \mathrm{~min}$; Fig. 7(E): $10-12 \mathrm{~min}]$. These processes often appear to be anterogradely translocated such that their base is moved forward along the thickening shaft [Fig. 7(E): 10-12 min]. Figure 7(D) shows a similar anterograde movement of a slight swelling on the shaft of the filopodium (17-19 min). In Figure 7(F), we see the extension of a second filopodium $(6 \mathrm{~min})$ and third 

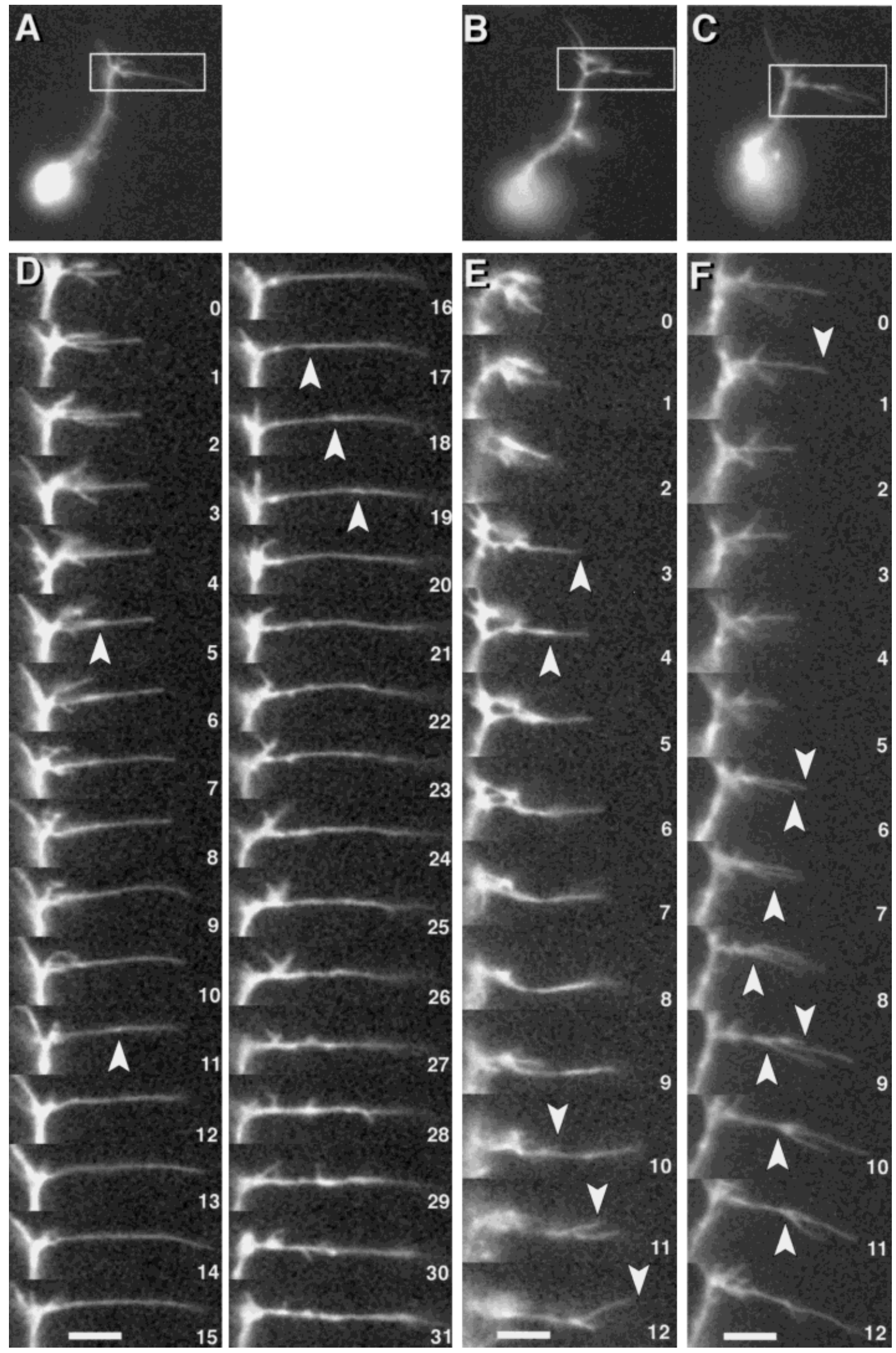

6
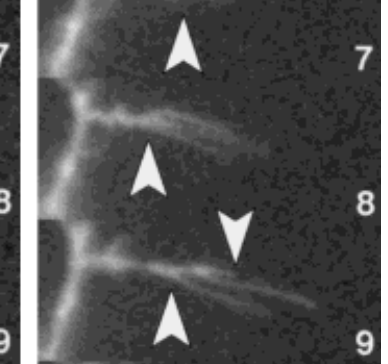

Figure 7 


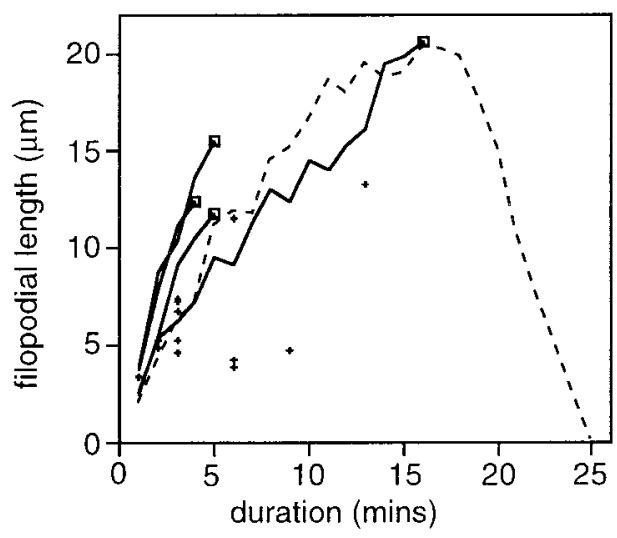

Figure 8 Peak filopodial length versus duration. The extension of four lateral filopodia that subsequently dilated (solid lines) is contrasted with 13 filopodia which did not dilate (crosses) where only the end point is plotted. The dotted line represents the unusually long filopodium indicated in Figure 5(A): 39 min.

filopodium (7 $\mathrm{min})$ whose bases are translocated forward $(8-11 \mathrm{~min})$.

The relative timing of formation of RP2's lateral branch was quite variable. In some cases, a lateral filopodium arose from the anterior tip of the axon [Fig. 5(A): $69 \mathrm{~min}$ ] and the axon turned immediately along its lateral path. In other cases, the growth cone extended well past the point at which the turn would eventually occur, only to be later resorbed as the lateral branch formed and matured (Fig. 4: 75-135 min). This inappropriate branch, which ranged from anterior to medio-anterior, was quite common ( $n$ $=16$ ) and could often emerge or reemerge long after the lateral branch had formed. The formation of this branch was, in some cases, clearly via the thickening of a single filopodium [Fig. 6(C)]. Another common morphological feature at this stage was a widening of RP2's growth cone into a fanlike shape [Fig. 6(A); see also Fig. 10: $56 \mathrm{~min}]$.

A common feature of all time-lapse sequences was the vigorous motility of the growth cone, trailing neurite, and cell as a whole. Time-lapse sequences in which the axonal environment of RP2 was made visible with Tau-GFP suggest that much of RP2's large-scale cellular movement simply reflects the movement of the entire cellular environment. In neurites, the bases of filopodia and larger branches were jostled both anterogradely and retrogradely.

As the leading edge of the axon continues out of the CNS, the trailing neurite becomes thinner and more even in diameter, adopts a smoother profile with fewer lateral processes, and becomes straighter with fewer acute angles. Filopodial activity is also reduced but does not entirely cease [Fig. 6(B)].

\section{Rates of Axon Elongation}

Average rates of axon elongation during in vivo timelapse sequences were approximately half those in whole embryos prior to fixation. Control experiments in which embryos were dissected and cultured in the absence of illumination showed a similar reduction in rate (data not shown), suggesting that this slowing of axon growth is due to culturing and not DiI labeling or photoillumination.

Growth rates in whole embryos were deduced by calculating RP2's mean axonal length in embryos fixed at 30-min intervals. RP2's rate of axon growth changes at $90 \mathrm{~min}$, increasing from 13.8 to $34.7 \mu \mathrm{m} / \mathrm{h}$ (Fig. 3). This change in rate coincided with the mean

Figure 7 Three examples of lateral dilation. (D-F) Detailed closeups of the boxed regions in (A-C), respectively. (D) A filopodium extends laterally and ventrally out of focus. Thickening of the shaft can be seen to initially occur at the base (arrowhead, $5 \mathrm{~min}$ ) and then at discontinuous locations along the shaft of the filopodium (arrowheads in 11, 17, 18, and 19; and at various locations in frames $21-31 \mathrm{~min}$ ). At frames 17,18 , and $19 \mathrm{~min}$, a small swelling is apparently translocated anterogradely at a rate of approximately $2 \mu \mathrm{m} / \mathrm{min}$. (E) A filopodium extends ( $3 \mathrm{~min}$, arrowhead), pauses (3-5 min), extends again (6-10 $\mathrm{min})$, and then retracts (11-12 $\mathrm{min})$. Thickening begins at the proximal end of the filopodium (arrowhead at $4 \mathrm{~min}$ ) and then laterally along the filopodium (5-9 $\mathrm{min}$ ). At time $10 \mathrm{~min}$, a secondary filopodium emerges from the side of the shaft and elongates, while its base is translocated forward at a rate of approximately $2 \mu \mathrm{m} / \mathrm{min}$ (arrowheads at 10, 11, and $12 \mathrm{~min}$ ). (F) A sequence in which three filopodia are involved in the lateral turn. A filopodium which has previously extended laterally (arrowhead at $1 \mathrm{~min}$ ) retracts $(1-5 \mathrm{~min})$, and then reextends (down arrowhead at $6 \mathrm{~min}$ ). Subsequently a second filopodium (up arrowhead at $6 \mathrm{~min}$ ) and third filopodium (arrowhead at $7 \mathrm{~min}$ ) emerge and extend laterally. The original filopodium appears to remain stationary (down arrowhead at $9 \mathrm{~min}$ ) as the bases of the other two filopodia are translocated forward (up arrowheads at $8-11 \mathrm{~min}$ ). By $12 \mathrm{~min}$, the original and third filopodia have retracted as the second filopodium continues to extend laterally. Bars $=5 \mu \mathrm{m}$. 
distance from RP2's soma to the lateral turn (19.8 $\pm 2.3 \mu \mathrm{m})$, suggesting that the growth rate increases once the axon is extending along the ISN.

Time-lapse sequences showed a similar trend. For each time-lapse sequence, a time was chosen when the first lateral filopodium had begun extension, and axonal growth rates calculated before and after that time. Rates up to the ISN averaged $7.5 \pm 3.4 \mu \mathrm{m} / \mathrm{h}$, with a range of 3.7-15.1 $\mu \mathrm{m} / \mathrm{h}$, while rates along the ISN averaged $19.9 \pm 7.8 \mu \mathrm{m}$, with a range of $8.8-$ $32.8 \mu \mathrm{m} / \mathrm{h}$. Thus, time-lapse rates up to the ISN were on the average $54 \%$ of rates seen in whole embryos, while rates along the ISN were $57 \%$.

\section{Filopodial Dynamics}

Filopodia were identified by an apparent uniform width of approximately $0.25 \mu \mathrm{m}$ (as measured in fluorescent images), uniform brightness, and rapid rates of extension and retraction. Statistical analysis [with the one exception shown in Fig. 5(A): $39 \mathrm{~min}$ ] was restricted to those filopodia whose extent was clear-i.e., filopodia whose tip and base were both visible. A total of 32 such filopodia were obtained from 8 of the 22 time-lapse sequences.

Filopodia were generally short-lived (4-17 min) but could persist for over $60 \mathrm{~min}$. Peak lengths reached by filopodia averaged $7.4 \mu \mathrm{m}$, and ranged from 3.5 to $20 \mu \mathrm{m}$ [Fig. 8; Fig. 4: 90 min; Fig. 5(A): $39 \mathrm{~min}$ ], implying that filopodia can potentially sample the environment several cell diameters away from their base (e.g., RP2's soma is typically about $7 \mu \mathrm{m}$ in diameter).

Filopodia extended and retracted at similar rates (Fig. 9), with a maximum rate of $5 \mu \mathrm{m} / \mathrm{min}$ for both retraction and extension. Filopodia often underwent repeated cycles of extension and retraction, particularly in directions of future axon growth. Filopodia could partially retract and reextend in new directions, such as in Figure 5(A) (76 min), in which the filopodium is seen to turn $180^{\circ}$. Filopodia often followed long curved paths [Fig. 5(A): $39 \mathrm{~min}$ ] and could undergo large lateral movements, bending in the middle and near their base.

These figures for maximum length $(20 \mu \mathrm{m})$ and maximum rates of extension $(5 \mu \mathrm{m}$ in $1 \mathrm{~min}$ ) are similar to those previously reported by Keshishian et al. (1993) for the dynamic behavior of filopodia at the leading edge of the developing segmental nerve (SNa).

Filopodia could apparently arise from all parts of the soma and axon and project in all directions, but tended to explore some directions more frequently than others: anteriorly along the forming longitudinal

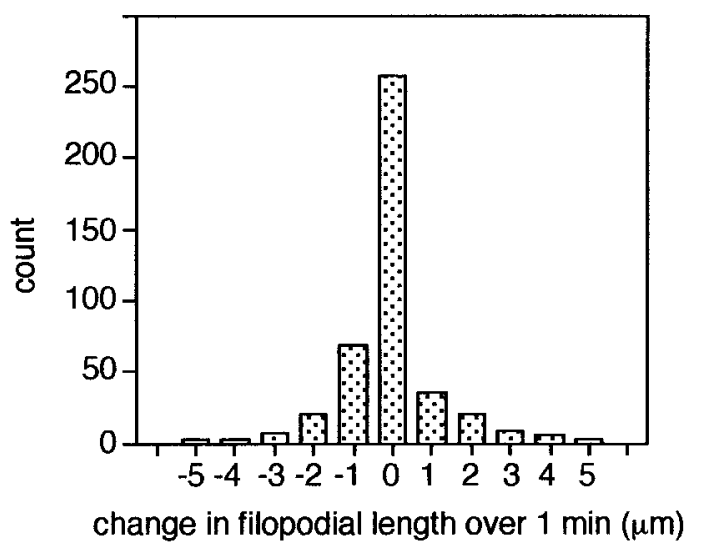

Figure 9 Distribution of changes in the length of filopodia over a 1-min interval. Frame-to-frame changes in length over the lifetime of each of the 32 filopodia included in the statistical analyses are pooled in this histogram. Rates of extension and retraction are similar with a maximum rate in both directions of $5 \mu \mathrm{m} / \mathrm{min}$.

connectives (Fig. 4: 5 and $35 \mathrm{~min}$ ), across the commissures [Fig. 6(B), where the filopodium was deduced to have crossed the midline] and antero-medially from the corner of the lateral turn [Fig. 6(C)]. Directions of future growth were often explored by multiple filopodia [Fig. 5(A): 76-88 min; Fig. 7(F): 5-9 $\mathrm{min}]$.

Filopodia extending laterally down the ISN prior to dilation tended to be longer than average (12.4 vs. 7.4 $\mu \mathrm{m})$ and to reach their maximum length more quickly and without long pauses or intermediate retraction (Fig. 8). Such rapid extension did not, however, invariably result in dilation. For example, the filopodium shown in Figure 5(A) (39 min) rapidly extended to a length of $20 \mu \mathrm{m}$ but did not dilate.

\section{Time-Lapse Observations in Embryos Expressing Tau-GFP}

Certain aspects of RP2's dynamic behavior were strongly suggestive of underlying cellular features providing substrates for RP2's growth cone. For example, it appeared likely that RP2's lateral filopodia were extending along axons in the nascent ISN. To test this, we used the GAL4-UAS activation system to produce embryos in which a subset of axonal pathways, including the ISN, was fluorescently labeled. To do this, flies were transformed with a UAS construct in which the microtubule binding protein, bovine Tau, was fused to a GFP double mutant, $\mathrm{GFP}^{65 / 167}$ (see Materials and Methods for details). This mutant is brighter than the wild-type GFP and has absorption and emission spectra more similar to 

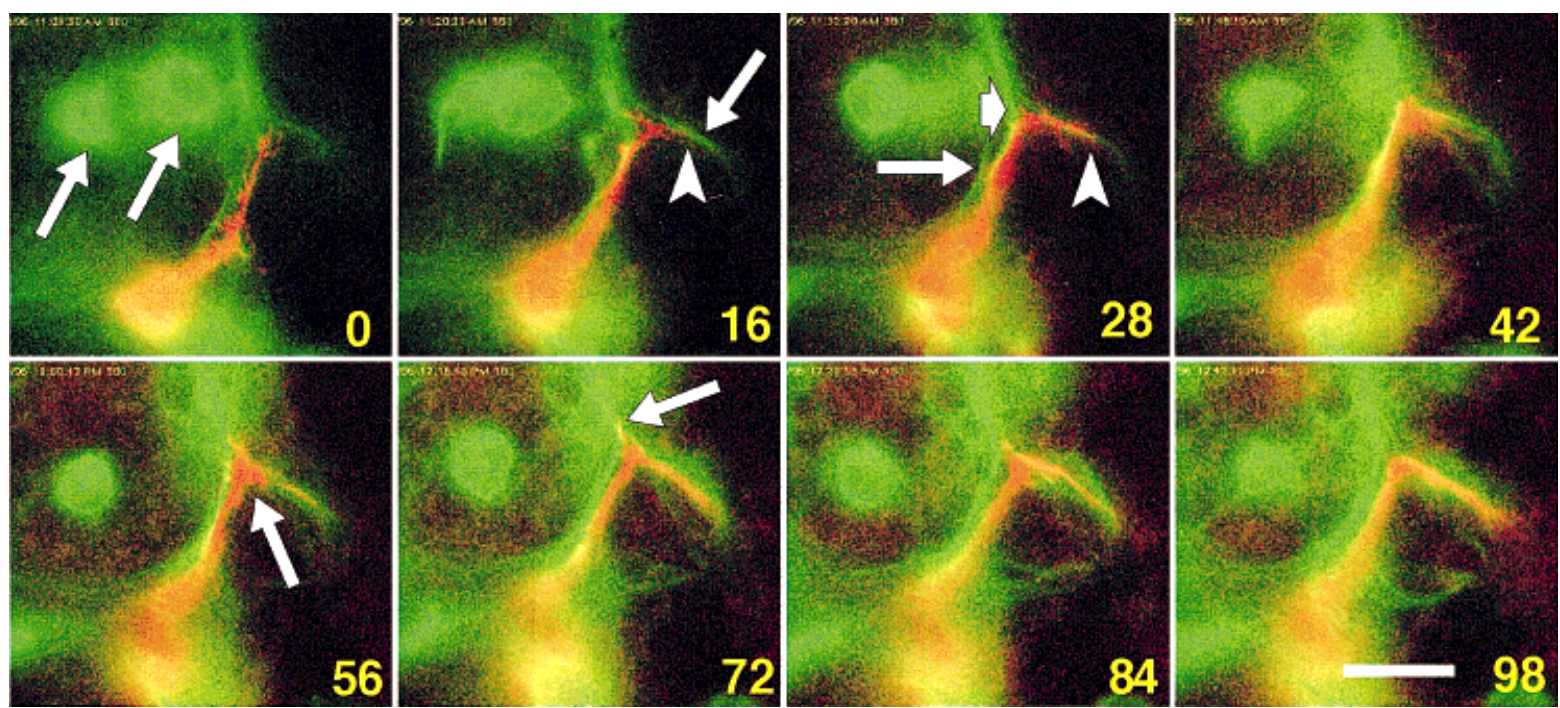

Figure 10 Time-lapse sequence of RP2 (red) and Tau-GFP-labeled cells (green). RP2 was injected with DiI in embryos expressing Tau-GFP. At 2-min intervals, an image of RP2 was captured using a TRITC filter set, followed $30 \mathrm{~s}$ later by an image of the Tau-GFP positive cells using an FITC filter set. The $\mathrm{ftz}_{\mathrm{ng}}$ regulatory region directs expression of GAL4 in a subset of cells including (MP1, dMP2, vMP2, aCC, and pCC). The GAL4 protein subsequently drives expression of the fusion protein Tau-GFP, which binds to microtubules. GFP-labeled features visible include nascent ISN (arrow at 16 $\mathrm{min}$ ), the MP1/dMP2 pathway (wide arrow at $28 \mathrm{~min}$ ), and pCC/vMP2 pathway (arrow at $28 \mathrm{~min}$ ), and two highly motile cells which appeared to be macrophages (arrows at 0 min). RP2 can be seen to extend a lateral filopodium along the ISN which subsequently dilates (arrowheads, 16-28 min). RP2's growth cone adopts a typical fan shape at the junction of the ISN and longitudinal pathways (arrow at 56 min) and can be seen to extend a mediolateral process between the MP1/dMP2 pathway and the proximal region of aCC's axon (arrow at $72 \mathrm{~min}$ ). Bar $=10 \mu \mathrm{m}$.
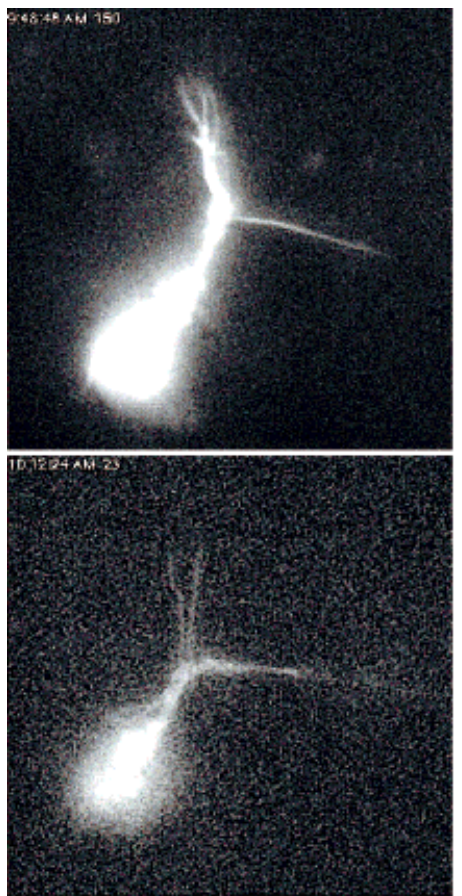

Dil
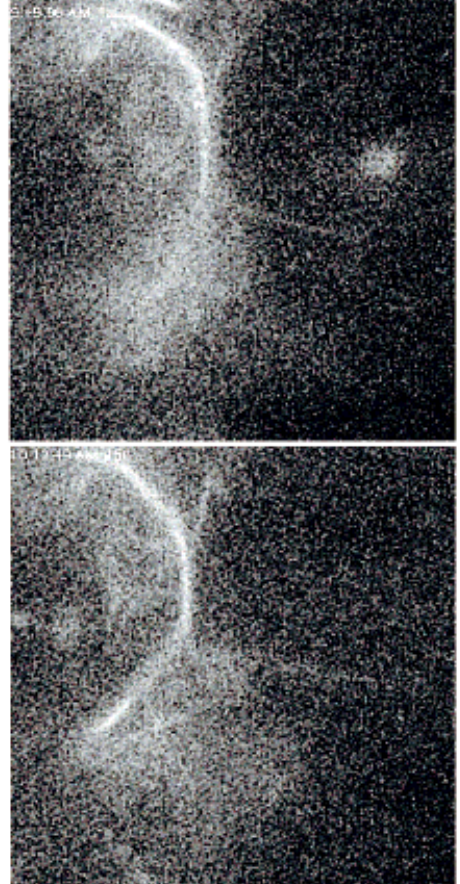

Tau-GFP

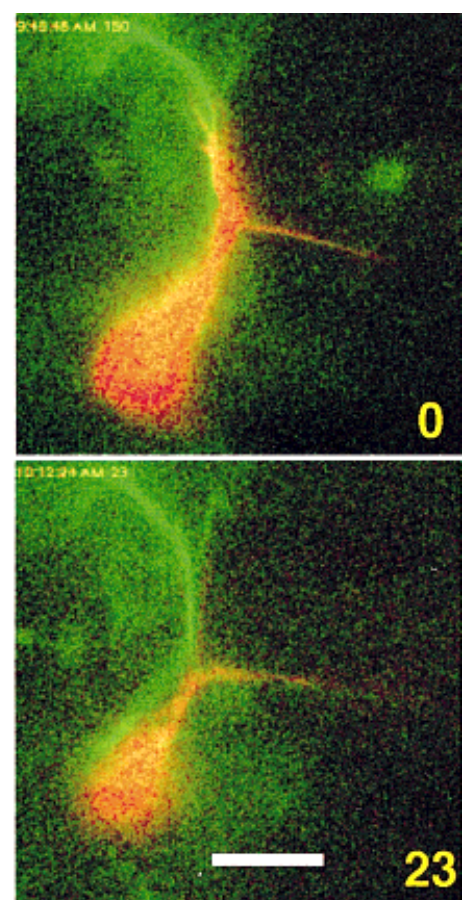

Composite

Figure 11 Dilation of lateral filopodium in Tau-GFP embryo. The neuron is shown before and after dilation of a lateral filopodium. As seen at $0 \mathrm{~min}$, the filopodium is coincident with the Tau-GFP-labeled ISN. Bar $=10 \mu \mathrm{m}$. 
FITC epifluorescence. The use of Tau targets the GFP fluorescence to microtubules, producing a strong signal in axons (Brand, 1995).

To drive expression of the UAS-Tau-GFP reporter, we used the $\mathrm{ftz}_{\mathrm{ng}}$-GAL4 effector (D. Van Vactor and C. S. Goodman, unpublished data; used in Lin et al., 1994, 1995) in which the GAL4 gene is placed under the control of the neurogenic enhancer of the fushitarazu gene (Hiromi et al., 1985). This control element directs expression in a segmentally repeated subset of cells which includes the pioneers of the longitudinal connectives (vMP2, dMP2, MP1, and $\mathrm{pCC})$, the pioneer of the ISN (aCC) and a subset of the RP motorneurons-including RP2 (Doe et al., 1988; VanBerkum and Goodman, 1995). As has been previously reported for the $\mathrm{ftz}_{\mathrm{ng}}$-GAL4 effector (Lin et al., 1995), we found that the levels of the reporter produced at a given stage varied greatly between different cells. At early stage 13, dMP2 and vMP2 consistently expressed Tau-GFP at high levels, making the $\mathrm{pCC} / \mathrm{vMP} 2$ and MP1/dMP2 pathways brightly fluorescent. In contrast, the ISN was usually only clearly visible in a few hemisegments per embryo. Having found such a hemisegment, RP2 was labeled with DiI and a time-lapse sequence collected. At 2-min intervals, an image of RP2 was captured using a TRITC filter set, followed $30 \mathrm{~s}$ later by an image of the Tau-GFP-labeled cells using an FITC filter set.

Using this technique, we collected seven sequences in which both the ISN and RP2's axon, as it navigates laterally out of the CNS, were visible. In each case, the lateral growth of RP2's axon was coincident with the ISN, and remained closely associated during subsequent cellular movements (Fig. 10). In those cases in which the dilation of a lateral filopodium was clear (Fig. 11), the filopodium was aligned with the ISN. GFP time-lapse sequences also showed that the common fan-shaped widening exhibited by RP2's growth cone in the vicinity of the ISN corresponded to the triangular region bounded by RP2's axon, the ISN, and the MP1/dMP2 pathway (Fig. 10: $56 \mathrm{~min}$ ). Finally, it was clear that the antero-medial process, another common feature of time-lapse sequences, was aligned with the MP1 pathway and the more proximal part of the ISN (Fig. 10: $72 \mathrm{~min}$ ), in the region in which these two pathways fasciculate.

\section{DISCUSSION}

We developed a system for time-lapse observation of the growth cones of identified neurons in the CNS of the Drosophila embryo. Our goal in using Drosophila is to study the general growth cone dynamics and specific axon pathfinding events of identified neurons in a well-characterized cellular environment, in both wild-type and mutant backgrounds. As a first step toward this goal, we characterized the wild-type, dynamic behavior of the motorneuron, RP2, as its axon migrates out of the CNS. In addition, we identified a specific steering event in which RP2's axon negotiates a sharp lateral turn by means of the dilation of lateral filopodia. Using one of the tools of Drosophila-the GAL4/UAS activation system-we determined that these lateral filopodia are coincident with the nascent ISN, suggesting that axons in the ISN might be providing a substrate for these filopodia.

In whole embryos, RP2's axon extends anteriorly toward the ISN at an average rate of $14 \mu \mathrm{m} / \mathrm{h}$ and then along the ISN at a rate of $35 \mu \mathrm{m} / \mathrm{h}$. These rates of axon growth are comparable to other systems: e.g., $16-52 \mu \mathrm{m} / \mathrm{h}$ in vivo in Xenopus (Harris et al., 1987), $40-50 \mu \mathrm{m} / \mathrm{h}$ in vivo in the mouse (Godement et al., 1994), and $17 \mu \mathrm{m} / \mathrm{h}$ (O'Connor et al., 1990) and 8 $\mu \mathrm{m} / \mathrm{h}$ (Myers and Bastiani, 1993) in the grasshopper. As reported for the grasshopper (O'Connor et al., 1990; Myers and Bastiani, 1993), cultured growth rates were slower than those in whole embryos.

The neurons of Drosophila are much smaller than those of the grasshopper, develop more quickly, and have filopodia which are shorter and less numerous. Despite these differences, patterns of growth and steering are similar in these two insects. O'Connor et al. (1990) described three types of axon migration and steering during ingrowth of the Ti1 pioneer neurons in the grasshopper limb bud: (a) veil extension-a flat organelle-free veil forms between filopodia and then undergoes engorgement; (b) filopodial dilation-a single filopodium thickens to become a newly formed neurite, advancing the axon in one saltatory jump; and (c) branch regression-multiple axonal branches form but only one is subsequently retained. In this study, we found filopodial dilation to be a major mechanism of both axonal migration and turning. Branch regression was also seen, with the formation and resorption of inappropriate branches being common. Veil extension, however, was not evident in this study. O'Connor et al. (1990) indicated that this mode of growth appears to occur primarily on homogenous, flat substrates. The lack of veil extension may reflect the heterogeneous nature of RP2's cellular environment. Alternatively, it is possible that veil extension does occur but is on a scale too small or too rapid to be detected by the resolution of this system.

The dilation events presented here show both similarities and differences to those described for the Ti1 neurons contacting guidepost cells (O'Connor et al., 1990; O'Connor and Bentley, 1993). In the grasshop- 
per, the filopodia that contact guidepost cells remain in contact with the guidepost cell as they dilate. Dilation occurs at the proximal end of the filopodium, at the tip-which expands into a palmate configuration as secondary filopodia emerge — and at discontinuous locations along the shaft.

We have observed thickening of the proximal ends of filopodia and thickening at irregular intervals along their shafts. However, we do not see a stabilization of the tip of the filopodium and a subsequent expansion of that tip into a palmate configuration. In our system, the filopodium usually continues to extend and/or retract as dilation proceeds. Nevertheless, the forward translocation of secondary filopodia and reextension of new filopodia from the tip of the thickened shaft does sometimes result in a palmate morphology in which a relatively narrow shaft is tipped with multiple filopodia [Fig. 7(F): $9 \mathrm{~min}$ ].

Another feature of dilation seen in the grasshopper but not apparent in our observations is the retrograde transport of aggregations during dilation (O'Connor and Bentley, 1993). We do, however, see an apparent forward translocation of features along the dilating shaft. We cannot discount the possibility that these events are actually the disappearance of one feature and the reappearance of a similar feature further along the dilating shaft; however, this seems unlikely given the frequency at which this phenomenon is seen. This phenomenon may reflect a recruitment of cytoskeletal material to the tip of a dilating filopodium, thereby facilitating further filopodial exploration in a favorable direction.

As seen in other systems (O'Connor et al., 1990; Kaethner and Stuermer, 1992; Halloran and Kalil, 1994), axonal migration rates differed markedly during different stages of growth; $14 \mu \mathrm{m} / \mathrm{h}$ anteriorly, and then $35 \mu \mathrm{m} / \mathrm{h}$ laterally. Time-lapse sequences, which show a similar trend, suggest that these differing rates may be due to differing lengths of dilating filopodia. Those filopodia that extended along the ISN and subsequently dilated were typically longer than the filopodia that extended and dilated during the anterior progression (12.4 vs. $5.3 \mu \mathrm{m})$.

Given the importance of filopodial dilation in RP2's navigation, we wondered whether those filopodia that dilated exhibited different dynamic behavior from other filopodia. Of all the filopodia that dilated, only the filopodia that extended laterally along the ISN showed a noticeable difference. These filopodia tended to be longer than average (12.4 vs. $7.4 \mu \mathrm{m})$, and to reach their maximum length quickly and without intervening pauses or retraction (Fig. 8). Other filopodia could reach similar lengths and extend as rapidly but tended to advance in shorter bursts of extension, interspersed with periods of retraction. One exception to this rule was the filopodium shown in Figure 5(A) (39 min), which apparently attained its maximum length in one rapid period of uninterrupted extension but did not dilate. Such selective elongation of filopodia extending along paths of future growth has previously been observed in fixed grasshopper embryos (David Bentley, personal communication) in both the CNS (Shankland, 1981) and along limb segment boundaries [Figs. 3(B) and 4(C) in Caudy and Bentley, 1987].

While the cytoskeletal rearrangements that occur during dilation have been described, relatively little is known about the signals that cause this dilation or the manner in which these signals are translated into cytoskeletal rearrangements (however, see Suter et al., 1998). Establishing reproducible dilation events in vivo can assist the analysis of this problem. For example, in the grasshopper, Bentley and colleagues were able to use known dilation events (e.g., filopodia from the Ti1 neuron contacting the $\mathrm{Cx} 1$ cell) to document the changing distributions of microtubules ( $\mathrm{Sa}-$ bry et al., 1991) and actin filaments (O'Connor and Bentley, 1993) during dilation. In our system, the best candidate for such a turning assay is the dilation of lateral filopodia. For this reason, we wished to identify possible substrates that might be involved in this dilation event with a view to ultimately perturbing them at a molecular level. Unlike the Ti1 neurons, RP2's axon navigates in an environment already populated by axon tracts. Using the ectopic expression of the fluorescent fusion protein Tau-GFP, we were able to show that RP2's lateral filopodia and the ensuing neurite are aligned with axons in the ISN. Further experiments such as ablation of neurons contributing to the ISN will be required to demonstrate a dependent relationship between RP2's lateral extension and specific axons in the ISN.

The authors thank Corey Goodman for the generous gift of the $\mathrm{ftz}_{\mathrm{ng}}$-GAL4 fly stock. They are most grateful to John Pines for his gift of plasmid pS65T,I167T, and to Catherine Davidson for help in generating the Tau-GFP transformants. For Internet access to time-lapse sequences, digital animations of the time-lapse sequences presented in Figures 4, 5, 7, and 10 are available as Quicktime movies at http:// www.une.edu.au/molbio/PWlab/TimeLaps.html.

\section{REFERENCES}

Brand, A. H. (1995). GFP in Drosophila. Trends Genet. 11:324-325.

Brand, A. H., and Perrimon, N. (1993). Targeted gene 
expression as a means of altering cell fates and generating dominant phenotypes. Development 118:401-415.

Bridgman, P. C. (1991). Functional anatomy of the growth cone in relation to its role in locomotion and neurite assembly. In: The Nerve Growth Cone. P. C. Letourneau, S. B. Kater, and E. R. Macagno, Eds. Raven Press, New York, pp. 39-54.

ButNer, K. A., and KirSChNER, M. W. (1991). Tau protein binds to microtubules through a flexible array of distributed weak sites. J. Cell Biol. 115:717-730.

Callahan, C. A., and Thomas, J. B. (1994). Tau- $\beta$-galactosidase, an axon-targeted fusion protein. Proc. Natl. Acad. Sci. USA 91:5972-5976.

Campos-Ortega, J. A., and Hartenstein, V. (1985). The Embryonic Development of Drosophila melanogaster. Springer Verlag, Berlin.

Caudy, M., and Bentley, D. (1987). Pioneer growth cone behavior at a differentiating limb segment boundary in the grasshopper embryo. Dev. Biol. 119:454-465.

Chalfie, M., Tu, Y., Euskirchen, G., Ward, W. W., and Prasher, D. C. (1994). Green fluorescent protein as a marker for gene expression. Science 263:802-805.

Desai, C. J., Sun, Q., and Zinn, K. (1997). Tyrosine phosphorylation and axon guidance: of mice and flies. Curr. Opin. Neurobiol. 7:70-74.

Doe, C., Hiromi, Y., Gehring, W., and Goodman, C. (1988). Expression and function of the segmentation gene fushi tarazu during Drosophila neurogenesis. Science 239:170-175.

Eisen, J. S., Myers, P. Z., and Westerfield, M. (1986). Pathway selection by growth cones of identified motoneurones in live zebra fish embryos. Nature 320:1-3.

Fischer, J. A., Giniger, E., Maniatis, T., and Ptashne, M. (1988). GAL4 activates transcription in Drosophila. $\mathrm{Na}$ ture 332:853-856.

Godement, P., WAng, L., and Mason, C. A. (1994). Retinal axon divergence in the optic chiasm: dynamics of growth cone behaviour at the midline. J. Neurosci. 14:70247039.

Goldberg, D. J., and Burmeister, D. W. (1986). Stages in axon formation: observations of growth of Aplysia axons in culture using video-enhanced contrast-differential interference contrast microscopy. J. Cell Biol. 103:19211931.

Goodman, C. S. (1996). Mechanisms and molecules that control growth cone guidance. Annu. Rev. Neurosci. 19: 341-377.

Halloran, M. C., and Kalil, K. (1994). Dynamic behaviors of growth cones extending in the corpus callosum of living cortical brain slices observed with video microscopy. J. Neurosci. 14:2161-2177.

Hammarback, J. A., and Letourneau, P. C. (1986). Neurite extension across regions of low cell-substratum adhesivity: implications for the guidepost hypothesis of axonal pathfinding. Dev. Biol. 117:655-662.

Harris, W. A., Holt, C. E., and Bonhoeffer, F. (1987). Retinal axons with and without their somata, growing to and arborizing in the tectum of Xenopus embryos: a time-lapse video study of single fibres in vivo. Development 101:123-133.

Heim, R., Cubitt, A. B., and Tsien, R. Y. (1995). Improved green fluorescence. Nature 373:663-664.

Heim, R., Prasher, D. C., and Tsien, R. Y. (1994). Wavelength mutations and posttranslational auto oxidation of green fluorescent protein. Proc. Natl. Acad. Sci. USA 91:12501-12504.

Hiromi, Y., Kuroiwa, A., and Gehring, W. J. (1985). Control elements of the Drosophila segmentation gene fushi tarazu. Cell 43:603-613.

Kaethner, R. J., and Stuermer, C. A. O. (1992). Dynamics of terminal arbor formation and target approach of retinotectal axons in living zebrafish embryos: a time-lapse study of single axons. J. Neurosci. 12:3257-3271.

Keshishian, H., Chiba, A., Chang, T. N., Halfon, M. S., Harkins, E. W., Jarecki, J., WanG, L. S., Anderson, M., Cash, S., Halpern, M. E., and Johansen, J. (1993). Cellular mechanisms governing synaptic development in Drosophila melanogaster. J. Neurobiol. 24:757-787.

LetourneAu, P. C. (1975). Cell-to-substratum adhesion and guidance of axonal elongation. Dev. Biol. 44:92-101.

Lin, C., and Forscher, P. (1993). Cytoskeletal remodeling during growth cone-target interactions. J. Cell Biol. 121: 1369-1383.

Lin, D. M., Auld, V. J., and Goodman, C. S. (1995). Targeted neuronal cell ablation in the Drosophila embryo: pathfinding by follower growth cones in the absence of pioneers. Neuron 14:707-715.

Lin, D. M., Fetter, R. D., Kopczynski, C., Grenningloh, G., and Goodman, C. S. (1994). Genetic analysis of fasciclin II in Drosophila: defasciculation, refasciculation and altered fasciculation. Neuron 13:1055-1069.

Mason, C. A., and Godement, P. (1992). Growth cone form reflects interactions in visual pathways and cerebellar targets. In: The Nerve Growth Cone. P. C. Letourneau, S. B. Kater, and E. R. Macagno, Eds. Raven Press, New York, pp. 402-423.

Merritt, D. J., and Whitington, P. M. (1995). Central projections of sensory neurons in the Drosophila embryo correlate with sensory modality, soma position, and proneural gene function. J. Neurosci. 15:1755-1767.

Myers, P. Z., and Bastiani, M. J. (1993). Growth cone dynamics during the migration of an identified commissural growth cone. J. Neurosci. 13:127-143.

O'Connor, T. P., and Bentley, D. (1993). Accumulation of actin in subsets of pioneer growth cone filopodia in response to neural and epithelial guidance cues in situ. J. Cell Biol. 123:935-948.

O'Connor, T. P., Duerr, J. S., and Bentley, D. (1990). Pioneer growth cone steering decisions mediated by single filopodial contacts in situ. J. Neurosci. 10:3935-3946.

Prasher, D. C., Eckenrode, V. K., Ward, W. W., PrenDergast, F. G., and Cormier, M. J. (1992). Primary structure of the Aequoria victoria green-fluorescent protein. Gene 111:229-233.

Ransom, R. (1982). A Handbook of Drosophila Development. Elsevier Biomedical Press, Amsterdam. 
Robertson, H. M., Preston, C. R., Phillis, R. W., JohnsonSchlitz, D., Benze, W. R., and Engels, W. R. (1988). A stable source of P-element transposase in Drosophila melanogaster. Genetics 118:461-470.

Sabry, J. H., O'Connor, T. P., Evans, L., Toroian-Raymond, A., Kirschner, M., and Bentley, D. (1991). Microtubule behaviour during guidance of pioneer neuron growth cones in situ. J. Cell Biol. 115:381-395.

Shankland, M. (1981). Development of a sensory afferent projection in the grasshopper embryo. I. Growth of peripheral pioneer axons within the central nervous system. J. Embryol. Exp. Morphol. 64:169-185.

Shields, G., and SANG, J. H. (1977). Improved medium for culture of Drosophila embryonic cells. Drosophila Inf. Service 52:161.

SinK, H., and Whitington, P. M. (1991a). Location and connectivity of abdominal motoneurons in the embryo and larva of Drosophila melanogaster. J. Neurobiol. 22: 298-311.
SinK, H., and Whitington, P. M. (1991b). Early ablation of target muscles modulates the arborisation pattern of an identified Drosophila motor axon. Development 113: 701-707.

Spradling, A. C. (1986). P-element mediated transformation. In: Drosophila: A Practical Approach. D. B. Roberts, Ed. IRL Press Ltd., Oxford, pp. 175-198.

Sretavan, D. W., and Reichardt, L. F. (1993). Time-lapse video analysis of retinal ganglion cell axon pathfinding at the mammalian optic chiasm: growth cone guidance using intrinsic chiasm cues. Neuron 10:761-777.

Suter, D. M., Errante, L. D., Belotserkovsky, V., and FORSCHER, P. (1998). The Ig superfamily cell adhesion molecule, apCAM, mediates growth cone steering by substratecytoskeletal coupling. J. Cell Biol. 141:227-240.

VanBerkum, M. F. A., and Goodman, C. S. (1995). Targeted disruption of $\mathrm{Ca}^{2+}$-calmodulin signaling in Drosophila growth cones leads to stalls in axon extension and errors in axon guidance. Neuron 14:43-56. 